\title{
Using Cultural Theory to Navigate the Policy Process
}

Richard Simmons, Senior Lecturer in Public and Social Policy, University of Stirling, r.a.simmons@stir.ac.uk

\begin{abstract}
Cultural Theory's (CT) four 'cultural biases' hold an intuitive appeal and empirical resonance for policy scholars as they seek to make sense of complex policy contexts. Yet research applications of CT are often hampered by superficial classifications and a lack of operationalisable measures. This article solves these problems, presenting valid measures in a 'compass' and 'map' to show how cultural patterns are both 'internalised' in individuals and 'institutionalised' in policy contexts. Key tensions here provide researchers with new interpretive tools to promote better questioning, learning and adaptation within particular policy environments, including opportunities for research impact through practical, 'institutional work'.
\end{abstract}

Keywords: Policy Implementation - Institutional Analysis - Policy Design — Institutional Work

\section{Introduction}

Lasswell's (1951) seminal notion of effective policy analysis combines the 'technical' tasks of 'the scientific study of problems' and 'policymaking around these problems' (Turnbull, 2008). Yet uncertainty and complexity are widely acknowledged to structure contemporary policy-making environments (e.g. Geyer \& Cairney, 2015). Phenomena such as bounded rationality (Simon, 1955) and 'wicked' policy problems (Rittel \& Webber, 1973) mean that sense-making often relies on more than simply scientific analysis. Grint $(2005: 1473)$ therefore observes that to make progress in confronting often intractable problems, 'the task is to ask the right questions rather than provide the right answers'. Complexity therefore places a premium on not only evidence and judgment, but also the ability to question, learn and adapt.

In the face of this complexity, institutions matter. Policymakers use institutions to establish and prioritise particular values, norms, rules and roles, thereby reducing the complexity of choice. Sometimes this can be a very positive process, inspiring a flow of ideas and fast-thinking-type solutions to policy problems that 'fit' with the policy context. However, sometimes institutions can get in the way - reinforcing values, systems and practices that no longer fit so well, and acting as blinders to emerging issues. So how do policymakers develop effective policymaking strategies when they are so limited by bounded rationality? Do their 'cognitive frailties' make them over-reliant on a combination of rational and irrational informational shortcuts to act quickly and make adequate decisions? If so, should institutions be designed to limit their autonomous powers, or instead should their ability to develop such heuristics be celebrated, and work be undertaken with them to refine such techniques? This article mobilises Cultural Theory (CT) to address such questions, allowing researchers to examine the role of institutions in structuring how policy actors make sense of their environment. 
The central problem addressed by this article is thus identified: policy is complex and mediated by institutions, and therefore 'institutional work' is needed to enhance the prospects of policy success. However, this raises some further key questions for policy researchers:

- What are the dominant institutional patterns that tend to structure policy problems and guide policymakers' response?

- How can institutional analysis assist in asking better questions in order to advance policy learning?

- How can research help identify and promote appropriate adaptations in particular policy contexts through the institutional work of 'creating, maintaining and disrupting institutions' (Lawrence \& Suddaby, 2006)?

This article addresses these challenging questions through CT's parsimonious framework, which constitutes institutions in four, rivalrous 'cultural biases' (hierarchy, individualism, egalitarianism and fatalism). This theory is popular and has been applied across (i) a diverse range of empirical fields (see Swedlow, 2014 for a review), (ii) different elements of the policy-cycle (from tasks of problem definition, modelling, alternative selection, and argument presentation to those of implementation and termination; e.g. Geva-May, 1997), and (iii) different levels and scales of activity (e.g. Mamadouh, 1999). In this way, the theory is claimed to provide some common frames of reference that benefit the work of policy scholars, including their engagement with practical policy actors (including professional advisors, commentators or other 'policy entrepreneurs' and those responsible for policy implementation - officials, managers and professionals).

Yet the alleged strength of CT's conceptual application can also prove a weakness if it results in superficiality. This includes what Mamadouh (1999) calls 'birdspotting' (whereby analysts spot illustrative examples of the four ideal-type categories while offering little by way of further explanation). This is grist to the mill of critics who claim that CT over-simplifies complex phenomena and so is insufficiently 'scientific' (e.g.Boholm, 1996; Tansey \& O'Riordan, 1999). Meanwhile, answers must also be found to the concerns of scholars seeking to use CT (who often struggle to systematically apply its theoretical refinements or engage with its state of the art), or practitioners who, anecdotally, sometimes struggle to get beyond the sense that, while 'somehow all this matters', it is hard in practical terms to 'know what to do' with the results.

Progress here has been further hampered by a lack of operationalisable measures. In response, this article places some new measurement tools at the heart of its discussion (cf. Simmons, 2016). These measures allow researchers to build a 'map' of institutional (in)congruence, comparing how things 'actually are' with how they 'should be' as a way of generating creative institutional dialogue and avoiding counterproductive institutional conflicts. They further allow researchers to understand the implications of policymakers following their 'internal compass' (based on informational and institutional shortcuts). In this way, these measures show the direction in which the compass is pointing and compare this with the guidance provided by the 'map'. Key tensions here provide researchers with better interpretive tools that promote more informed institutional analysis in particular policy environments. In turn, this enables researchers to consider policymakers' ability and willingness to ask better questions as they navigate their policymaking environment, as well as providing practical opportunities for research impact through more grounded discussions about practical action and 'institutional work'. 
In short, this article uses CT to shine a light on these institutional dynamics and provide policy researchers with some useful heuristics to navigate this terrain. In what follows, the article first introduces the CT framework and some of the tools it provides in helping researchers make sense of institutions; framing different institutional logics and how they relate to one another. The problems of measurement in $\mathrm{CT}$ and how these are addressed by the new measurement tool are then discussed. Next, the article's key metaphors of a 'map' and a 'compass' are used to set out a key distinction between how cultural patterns are both 'internalised' in individuals and 'institutionalised' in policy contexts. Discussion follows on how this helps researchers to understand the navigation of both change and obstacles to change. Finally, the article addresses a further key distinction: between more abstract and intangible 'institutional' understandings and their more grounded and material 'practical' applications. This considers the added value of this analysis for (i) asking better questions, and (ii) learning from the answers to (iii) suggest adaptations that fit better with today's complex policy contexts. In combination, the above analysis aims to provide a memorable 'route map' for policy scholars seeking to conduct new empirical research as well as new audiences such as students, practitioners, and scholars from other disciplines.

\section{Understanding Cultural Theory}

Cultural Theory (CT) has emerged as an important tool for policy analysis (Hood, 1998; Geva-May, 2002, Klitgaard, 1997; Hoppe, 2011; Swedlow, 2002; 2011; 2014; 2017; 6 \& Swedlow, 2016). Following Mary Douglas' exposition of the theory (1970; 1982; 1992) and Thompson et al's (1990) seminal refinement of it, there have been numerous attempts to develop its insights into the institutional factors governing policy effectiveness (e.g. Wildavsky, 1987; Thompson, 2008; 6, 2003). Links between culture and institutions are important; in short, 'culture consists in institutions, which preserve cultural values and norms and give them authority' (Brett 2000; cf.Douglas 1987). In turn, this provides the context for social interaction, shaping people's preferences and justifications so that 'everything human beings do or want is culturally biased' (Mamadouh, 1999:396; see Figure 1). Yet how do people acquire 'cultural bias'? And what types of bias are we talking about?

[Figure 1 about here]

For its proponents, the CT framework provides parsimonious answers, in a clear and comprehensive set of dimensions and propositions that are together claimed to 'grasp the fundamental nature of sociality' (Mamadouh 1999:396). CT's success derives from the intuitive importance of these two high-level dimensions and empirical resonance of the four cultural 'biases' or 'worldviews' that result from their juxtaposition.

[Figure 2 about here]

The two high-level dimensions are represented as the vertical and horizontal axes in Figure 2. Each may be strong or weak. In strongly-regulated cultures actors are heavily constrained by rules and ascribed behaviour; in weakly-regulated cultures much less so. Meanwhile, in strongly-integrated cultures actors are connected and included in group membership; in weakly-integrated cultures much less so. As is now widely-known, when these high-level dimensions are combined, the CT framework reveals four 'cultural biases' or 'worldviews', each of which describes different idealtypical patterns of social relations: 
- Hierarchy (strong regulation, strong integration) sums up a bureau-professional relationship in which the policy process and policymakers' behaviour are defined by strict rules and procedures that govern particular roles.

- Individualism (weak regulation, weak integration) constructs policymakers (and the targets of policy) as more autonomous, utility-maximising individuals, who need to be incentivised by appeals to their self-interest.

- Egalitarianism (weak regulation, strong integration) is represented by 'mutualistic' forms of relationship, in which policy may be co-produced through more collective norms and processes (but may yet flounder in the face of excessive homophily/groupthink or intra/inter-group conflict).

- Fatalism (strong regulation, weak integration) sees social relations as imposed by external structures, and pressures to conform with any social group are weak. This leaves individuals isolated and withdrawn within a policy system where 'co-operation is rejected, distrust widespread, and apathy reigns' (Hood, 1998:9).

Researchers have applied CT readily to define some key battlefields for policy debate. A classic exemplar is the well-known conundrum of the 'tragedy of the commons' (Hardin, 1968; cf. Wildavsky, 2006:228; Buck, 1989). Here, in the absence of regulation to prevent the over-grazing of common-land, is the best answer hierarchical oversight and regulation by formal authorities (as Hardin suggests)? Or the peer oversight and moral regulation of egalitarian institutions (as suggested by Ostrom, 1990)? Should the land be privatized and regulated by the 'invisible hand' of a market in which motivated individualists are left to maximise their own utility? Indeed, is there any point in actively attempting to regulate, or should another hand - that of 'fate' - be left to prevail? Or, finally, should some 'hybrid' solution be constructed? While each scenario is theoretically possible, acceptance of each provokes a different set of detailed prescriptions for policy action, for which the relative advantages and disadvantages would need to be considered. Similar variations in the realms of possibility exist for myriad other policy issues, many of which are complex in modern policy contexts.

Beyond this, CT has developed various tools and resources of use to scholars in their struggles for more reflective research and analysis:

(i) 'Static' CT analysis (what life looks like from within each ideal-type)

(ii) 'Dynamic' CT analysis (what to look for when ideal-types interact)

(iii) Measurement tools (to strengthen such analysis)

With regard to 'static' analysis, CT is now established as much more than a cultural classification scheme, yet its value as such should not be underestimated. Numerous ideal-type comparisons, often in the form of tables, have been compiled in CT research (see Figure 3 for a well-known example). Such 'static' analysis is an essential part of sensitising researchers to the fundamental, ideal-type building blocks of CT- allowing insights into what life looks like from within each idealtype. However, it says nothing of the prevalence of particular ideal-types in a particular context, nor of the dynamics resulting from their inter-dependence. Many scholars are aware of this, yet 
'birdspotting-type' accusations still persist in discussions and peer review. Cultural analysis should not stop here.

[Figure 3 about here]

By contrast, 'dynamic' CT analysis examines what happens when ideal-types interact. Such analysis is accommodated in some key theoretical propositions (Thompson et al, 1990). First, the 'requisite variety condition' states that elements of all four ideal-types should be expected to be present within a policymaking system at any time. Second, the 'compatibility condition' states that viable patterns arise when social relations and cultural biases are mutually supportive of each other - and vice-versa (Thompson et al, 1990).

Together, these propositions explain two important patterns between the four ideal-types: those of relative dominance and subordinacy, and those of relative congruence and dissonance. With regard to the former, the four ideal-types' continuous rivalry in any policy context means that anomalies can breed and grow $(6,2003)$. This risks the system becoming unstable and the 'destructive potential of the inevitable tensions and conflicts' being released $(6,2003: 402)$. Such perspectives develop those of the currently-dominant prescriptive approach for policy analysis using CT, namely that of 'clumsy solutions' (Verweij \& Thompson, 2006; Verweij, 2011) in which the voice of different idealtypes is able to be heard and responded to (as opposed to one voice being dominant and drowning out the others; Thompson, 2008). Achievements here involve the cultivation of a 'polyrational imagination' that, by embracing more than a single ideal-type, takes institutional pluralism seriously (Davy, 2016). In terms of institutional analysis, this involves standing back to reflect on how the weaknesses of one worldview might be compensated by the strengths of another (Hoppe, 2011), so that 'the impossible becomes possible when you see it from a different point of view' (Stewart, 1996). The lesson here is that failing to recognise other perspectives can cause considerable problems - wearing 'institutional blinkers' is not an option. For scholars interested in robust CT analysis, this requires careful critical reflection to avoid the selective acknowledgement and reporting of (i) particular cultural voices, or (ii) conversations between them.

For example, in relation to climate change, Thompson (2003) identifies three competing 'stories' associated with different worldviews. In what he calls the 'egalitarian story', protagonists point to the profligate consumption and production patterns of the global North as the fundamental cause of global climate change. By contrast, the 'hierarchist' story asserts that of uncontrolled population growth in other regions of the world places local and global eco-systems under pressures that quickly become dangerously uncontrollable. Meanwhile, the 'individualist' story suggests that the price of natural resources is the most important factor in both controlling demand and footing the bill for environmental protection. In sum, while each story contains its own internal logic, it stands in tension with the others and holds only part of the solution to this policy problem. Institutional pluralism ensures that the institutional blinkers are removed and appropriate attention and weight attached to each of these stories in allowing more effective policy solutions to emerge.

When a state of congruence is achieved in a balance of perspectives, the above tensions and conflicts are minimised. Congruence is about the 'fit' between perceptions of how much of each ideal-type there actually is in any given context, and how much there should be for the system to be optimally viable (Simmons, 2016). A key task for research here is to understand how any incongruence can be successfully measured and managed. For example, to what extent does analysis 
indicate an excess or deficit of hierarchy? Or of individualism, egalitarianism or fatalism? And how might we address significant excesses or deficits? CT provides a way of framing more critically reflective research on these issues - whether this is reflection 'in-action' (thinking carefully about the situation that is unfolding), 'on-action' (thinking retrospectively about the effects of how a situation was handled), or 'for-action' (thinking about future actions with the intention of making changes or improvements) (Schon, 1983; Killion \& Todnem, 1991). In other words, CT research not only has to show that its information is valid (at the nexus between 'data', 'questioning' and 'reflection in-action'), but that it is insightful (at the nexus between 'interpretation', 'learning' and 'reflection on-action') and of practical use (at the nexus between 'findings', 'adaptation' and 'reflection for-action'). Hence, it is highly feasible for scholars to ask, for a particular policy context:

\begin{tabular}{|c|c|}
\hline $\begin{array}{l}\text { 'How would things appear if I were to look at them through the lens of } \\
\text { hierarchy, individualism, egalitarianism, or fatalism?' }\end{array}$ & \multirow{2}{*}{ 'Reflection in-action' } \\
\hline $\begin{array}{l}\text { 'How much does what I actually observe around me look more or less } \\
\text { like one or other - or some combination - of these possibilities?' }\end{array}$ & \\
\hline $\begin{array}{l}\text { 'To what extent does that reflect a pattern of dominance and } \\
\text { subordinacy, or of congruence and dissonance?' }\end{array}$ & \multirow[b]{2}{*}{ 'Reflection on-action' } \\
\hline $\begin{array}{l}\text { 'What effects does that produce in terms of behaviours, or 'operational } \\
\text { practices'?' }\end{array}$ & \\
\hline 'Should any action be taken as a result?' & \multirow{2}{*}{ 'Reflection for-action' } \\
\hline 'If so, what should be done?' & \\
\hline
\end{tabular}

In sum, sensitisation to each of CT's four worldviews (through static analysis) is an important step towards deeper reflection about their (dynamic) interaction. Static CT analysis increases the power of this reflection (allowing scholars to see things more clearly and quickly), while dynamic CT analysis determines the direction of it (allowing them to weigh the implications). Importantly, as Swedlow (2002:275) points out, this enables policy researchers to consider such things as:

\section{(i) When policy change requires cultural change}

(e.g. research examining 'Experience-Based Design' shows that change from a hierarchical to a more egalitarian mindset was required before medical professionals would engage in a process of more person-centred and co-productive healthcare service design; Bate \& Robert, 2007)

(ii) When cultural change makes policy change more likely

(e.g. research shows that direct challenges to the appropriateness of traditional job classifications on the basis of stereotypical gender roles have led to the deinstitutionalization of this practice in many organizations; Oliver, 1992)

(iii) Which policies are likely to reproduce and reinforce existing cultural configurations (e.g. research shows how self-regulating professions use codes of conduct and codes of ethics to clarify the responsibilities of members and articulate standards; Perlis \& Shannon, 2012)

\section{(iv) Which policies are likely to challenge and reshape them}

(e.g. research shows how smoking laws and seat belt enforcement have established and reinforced new normative patterns in the UK; Knott et al., 2008)

However, while CT's conceptual and theoretical tools travel easily across a wide range of contexts, levels and scales, the same cannot yet be said for its measurement tools (see Ripberger et al, 2015 
for a review). Although this may seem curious, some brief explanations are offered here before a way forward is suggested.

Measurement to support static CT analysis is difficult for at least two reasons. First, there are issues of (de)contextualization. For example, early attempts to produce generalised measures of cultural bias used a decontextualized survey instrument that was free of any social context (Dake, 1991; 1992). These attempts were largely unsuccessful (Ripberger et al, 2015). Critics were unsurprised, arguing that cultural biases must be considered in combination with contextualised patterns of social relations (e.g. Rayner, 1992). However, contextualized measures bring problems of their own; both in lacking wider comparability and in the cost and effort of developing bespoke measures that accurately capture the necessary detail. To further complicate matters, Swedlow $(2007 ; 2017)$ raises issues of what Douglas (1966) calls 'purity' and 'pollution'. In short, this means that any internal consistency in people's cultural ideal-type worldviews (i.e. 'purity') may be compromised as it mingles with and is influenced by other worldviews (i.e. 'pollution'). As it does, this pollution may again confound accurate measurement.

In contrast, Ripberger et al's (2015) review of the field suggests that the prospects of measurement to support dynamic CT analysis appear to have recently become more promising (including improvements in face, construct, concurrent and predictive validity). Importantly, a key factor in this is stronger recognition of the theoretical justification for measuring cultural bias in ways that also takes into account patterns of social relations and actual behaviours.

\section{Overcoming Challenges of Measurement}

One new approach, developed by this author (Simmons, 2016), seeks to overcome the above challenges of measurement. This approach uses CT to 'map' the degree of cultural congruence in different policy contexts. It is re-presented briefly here as a way to both operationalise CT and to build on the 'map' and 'compass' metaphors outlined in the introduction (to which we also return in the next section of the article).

In short, Simmons' (2016) research was conducted in a public administration context, focusing on public service users' relationships with their service provider and the effects of this on their willingness and ability to 'voice' their opinions (cf.Hirschman, 1970). CT was used as a theoretical lens for understanding how cultural-institutional patterns serve to facilitate or constrain user voice. The results showed these effects to be considerable. In what follows, however, the focus is more on the approach taken by Simmons' (2016) and how this helps overcome many of the objections made against earlier attempts to operationalise $\mathrm{CT}$ in survey research:

- First, the instrument was based on a deeply contextualised approach; namely, a preliminary phase of qualitative fieldwork in three locations from which detailed analysis of semistructured interviews $(\mathrm{N}=80)$ elicited four key themes in the patterns of social relations that mattered most to service users (namely 'courtesy and respect'; 'how knowledge is valued'; 'how fairness and equity issues are resolved'; and 'how rules are set and policed').

- Second, issues of purity and pollution were addressed by taking an open, non-judgmental approach. Each of the four key dimensions was operationalized equally against each of the four CT ideal-types. This resulted in four statements being developed for each of the four key dimensions to assess users' normative perceptions of how things should be. Survey 
respondents in three different public service settings (social care $(\mathrm{N}=116)$; leisure services $(\mathrm{N}=318)$ and public housing $(\mathrm{N}=109))$ were then invited to rate each individual statement on a 5-point Likert-type scale.

- Third, given that congruence is about the 'fit' between perceptions of how much of each ideal-type there 'actually is' in any given context, and how much there 'should be' for the system to be viable, each statement was re-worded according to the former in a second set of statements (see Figure 4). Ratings for each statement were then aggregated and presented on a radial plot (see Figure 5). Similarities in respondents' ratings of how things 'actually are' and how things 'should be' represent greater congruence; differences represent greater dissonance (see Figures $6 a$ and $6 b$ ).

[Figure 4 about here]

- Fourth, account was given to the theoretical justification for measuring cultural bias in ways that also takes into account patterns of social relations and actual behaviours. The statements were explicitly intended to capture the nature of a set of specific social relations rather than the essence of each cultural bias. In this way, differences in users' scores against these statements were used only in relative, rather than absolute, terms. Nevertheless, it is only these relative differences that are important in defining the extent of congruence and dissonance.

- Finally, adding to the 'face' and 'construct' validity in the above approach, Simmons (2016) was also able to show its 'predictive' validity in terms of how notions of congruence correlated with other survey items measuring (i) respondents' perceptions of the quality of service relations, (ii) service performance and (iii) the availability of 'good opportunities' for user voice.

[Figure 5 about here]

[Figures $6 \mathrm{a}$ and $6 \mathrm{~b}$ about here]

In defining conditions of cultural 'congruence' and/or 'dissonance', this map is able to identify the terrain in which researchers and policy actors attention might be productively focused, and where particular forms of action might be most appropriate (cf. Simmons, 2016). 6 and Swedlow (2016: 872) describe Simmons' (2016) approach as an 'innovative operationalization' and 'methodological advance' for CT. Specifically, it allows a response to some key questions, such as: 'How would we know when the prevailing 'institutional logics' have become suboptimal in the governance of problems in our particular context?' and 'How would we use CT to know which direction(s) to move in?'.

For example, in Figure $6 \mathrm{~b}$ congruence is most evident in the case of 'day care', where the shapes formed by the 'is' and the 'should be' statements are the most similar. By contrast, in the 'leisure' case there appears to be a particular blind spot in relation to egalitarianism (and to a lesser extent individualism). Meanwhile, in the 'housing' case there is work to do to close the gap on at least three dimensions - individualism, egalitarianism and fatalism. Knowing such things allows policy actors to understand more about what action to take. In this regard it should be noted that, even in the day care case, the relative congruence observed is an achievement that must be actively maintained. In the other cases, however, some form of change is required. Knowing this can spark the important 
process of 'questioning' (Turnbull, 2013). In the leisure case, for example, 'what might it look like to be more egalitarian?'.

There remains at least one of the above objections that Simmons' (2016) approach does not overcome. This is the cost and effort of developing bespoke measures - even if these support more productive insights and reflections on the institutional factors governing policy effectiveness. In response, a purist might argue that 'organisations run surveys all the time on various issues; why not invest here?'. However, in an environment of financial resource constraint, such contentions must be acknowledged.

More fundamentally, there is another, more functional problem. As Argyris (1976:365) observes, effective learning requires both 'valid information' and 'receptivity to corrective feedback'. However, while the CT 'map' claims to provide valid information, there is no guarantee that policy actors will be receptive to this feedback. This brings back into the discussion how these actors are influenced by their 'internal compass'. An actor's 'internal compass' takes in the values and worldviews that are compatible with their approach toward particular policy issues (6 \& Swedlow, 2016). As a reference point from which everything can be checked to determine a sense of 'rightness' (Smythe \& Norton, 2007:74), this internal compass directs their 'judgement' (Vickers, 1965) and 'fast-thinking' (Kahneman, 2011). No bad thing, perhaps - unless this starts sending them off-course. Yet faulty compass readings arise when thought-styles become 'cultural blinkers', plotting a course ahead that blocks out other constructions of the problem. In this way, the patterns of relations and cultural bias that are internalised in individuals sometimes form such 'credible commitments' that they hold actors back from exploring alternatives or distort their policy orientation and navigation. Examples abound, such as commitments to market principles of 'value for money' in public procurement that ignore other policy goals such as carbon emission issues, or commitments to restrictive planning regulations and/or protection of the green belt that ignore other policy goals such as the provision of affordable housing.

A helpful addition to Simmons' (2016) measures of the degree of institutionalisation of cultural biases in the 'map' would therefore be a measure of the extent of people's internalisation of such perspectives in their 'internal compass'. Value may be claimed here for comparability in the 'framing of cultural configurations' - or how policymakers use institutions - in both 'compass' and 'map'. Arguably, measurement of the compass therefore might therefore involve a relatively straightforward extension of Simmons' (2016) methodology by simply asking respondents to both 'rank and rate' the competing attitude statements in each section of Figure 3. Nevertheless, a more reliable technique might be using $Q$ methodology with these statements (Brown, 1993; Durning, 1989). A robust method for combining the sorting and ranking of statements with factor analysis and hierarchical cluster analysis, this approach has the potential to add further insights.

In combination, having a means of 'measuring' the compass as well as the map provides a more detailed understanding of the dynamics governing the 'tension-field' in particular policymaking contexts. This includes the directions in which 'receptivity to corrective feedback' is lacking, thereby moving towards or away from particular patterns of social relations and facilitating/constraining 
particular movements on the map that might be needed to effect appropriate adaptations and change. These issues form the focus for the next section of this article.

\section{Using the 'Map' and the 'Compass' for Policy Analysis and Policy Navigation}

CT researchers' ability to measure differences in the extent to which patterns of social relations and cultural bias are both 'internalised' in individuals (i.e. in their 'internal compass') and 'institutionalised' in particular policy contexts (i.e. in ways that can be 'mapped') is important. Earlier we asked how policymakers develop effective policymaking strategies when they are so limited by bounded rationality, and whether their 'cognitive frailties' make them over-reliant on a combination of rational and irrational informational shortcuts to act quickly and make adequate decisions. Measurement helps researchers to answer these questions and reduce the need for such shortcuts. Indeed, given that policy actors rarely possess an infallible 'internal compass', a reliable 'map' provides them with an invaluable tool against which to check they are on track. As Turnbull (2013: 125) asserts, 'individuals hold the capacity to reflect upon and problematize their place within a field, for example by reflecting upon their own entrenched ways of doing things'. CT analysis supports this by helping scholars to demonstrate the extent to which policy actors are able to orientate themselves 'appropriately' toward policy problems and navigate the actions that might be taken to address them. In this sense, this article addresses questions raised in the introduction about the extent to which institutional patterns tend to structure policy problems and guide policymakers' response, and how institutional analysis can help by identifying better questions to promote policy learning.

However, two questions remain. First, if policy actors are both over-reliant on their internal compass and unreceptive to corrective feedback, how might institutions be designed to limit their autonomous powers? Meanwhile, if they are more receptive, how might work be undertaken with them to recalibrate their compass readings? In either case, CT measurement can be used to help ensure that the direction in which their internal compass points them is not too far away from where their attention is most needed. The fit between their compass readings and the problem context is therefore significant. If there is a good fit, fast thinking is more likely to lead to successful action strategies and policy navigation. However, if this is not the case, a different approach may be demanded. In this way, the 'map' and 'compass' are each useful tools, but must be harnessed and used in conjunction for effective navigation. For example, in his highly influential text 'Beyond Rational Management', Quinn (1988: xv) distinguishes between one decision-making frame that is 'purposive, static and entropic', and another that is 'holistic, dynamic and generative'. Policymakers' 'purposive frame' is the equivalent of their 'internal compass'; in their 'holistic frame' they map a wider range of perspectives. Importantly, Quinn (1988) observes that 'exceptional individuals' do not achieve excellence by using one or other frame but by using both in conjunction.

While this may be so, if one or other of the 'compass' or 'map' is perceived to be unreliable, it is likely to be disregarded. So how do relationships between the two pay out? Notions of 'purity' and 'pollution' (cf. Swedlow, 2017) are invoked here to explore the field of relationships between the compass and map. This centres particularly on their different 'purity claims'. Moreover, in assessing how the nature of the boundary between the compass and map may vary at different times in the policy process, Stirling's (2006: 101) distinction between the 'opening up' or 'closing down' of policy discourse is also informative: 
'If it is about 'closing down' the policy process, then the aim is to assist decision-making by cutting through the messy, intractable and conflict prone diversity of views and develop in a clear authoritative prescriptive recommendation... On the other hand, if it is about 'opening up' the process, the focus is on revealing wider policy discourses and interpretations of the available evidence'.

How might we encapsulate and understand these distinctions? In short, the 'internal compass' is careful to keep its boundaries high, as both a reference point and a container for 'principled' judgment. In Quinn's (1988) terms, it is 'purposive, static and entropic'. The map's 'polyrationality' can therefore feel confrontational and its 'corrective feedback' challenging, which in turn affects 'receptivity'. At the above point of 'closure' of the policy process, where a clear decision is needed, it therefore filters this polyrationality, which it views as 'noise pollution'. This practice of filtering underpins its purity claim; that it enables decision-makers to see and think more clearly in the sensemaking process.

By contrast, the 'map' maintains more open boundaries to develop an overview of the policy context. It is a checkpoint for patterns of congruence and dissonance, remaining open to all perspectives and possibilities without placing judgment on them. It filters this information using polyrationality. This practice of filtering underpins its purity claim of providing 'valid information' (Argyris, 1976), thereby simplifying complexity and providing clarity for 'better-informed' decisions. In Quinn's (1988) terms, this process is 'holistic, dynamic and generative', providing useful 'corrective feedback' to the process of 'reflection for-action'.

It should be noted here that 'objections to' or 'acceptance of' each other's claims can provoke either conflict or co-operation. Hence, the discourse from compass to map may be: 'Don't stay open! Decisions have to be made sometime and scanning the environment is no longer helpful!' The response may be: 'OK, but we need to have confidence in those decisions. Show that you have taken our inputs seriously if you want us to quieten down'. Conversely, the discourse from map to compass may be: 'Don't stay closed! Things are complex and uncertain and you need to stay aware!'. Yet here, the response may be: 'OK, but we need to have confidence that you have 'valid information' if we are going to be convinced to open up'.

At the heart of this are the key issues of questioning, learning and adaptation. In sum, (i) each perspective asks and answers questions differently, and (ii) each holds the key to different influences on the effectiveness of learning: i.e. 'valid information' (map) and 'receptivity to corrective feedback' (compass). In learning to co-operate, as successful policy navigation necessitates, adaptation therefore becomes a 'dance', with at least two elements: First, as either the 'holistic' frame (map) or 'purposive' frame (compass) is pulled forward, so the other is pushed into the background; Second, at times when the policy process is 'opened up' the map is more likely to be foregrounded, and viceversa. For conflict to be avoided and greater co-operation to be made possible, the focus therefore must be on greater acceptance of each other's 'purity claims'.

In sum, researchers' knowledge of policy actors' compass bearings are important. This can show how open or closed actors are to particular forms of corrective feedback. This might lead to productive discussions with policy actors about engaging in critical reflection of how well their compass readings 'fit' with the policy context. However, such conversations require researchers to also ensure that institutional maps are as accurate as possible and that findings of institutional 
(in)congruence are communicated clearly as a way to help actors in navigating the policy terrain. For 'research with impact', this task could include identifying opportunities for change through more grounded 'institutional work'.

This brings us to the final question identified in the introduction: that of how research can help identify and promote appropriate adaptations in particular policy contexts through the institutional work of 'creating, maintaining and disrupting institutions' (Lawrence \& Suddaby, 2006). For some, this is a sticky question: if institutional issues underpin the policy context, in real terms what can be done? 'Culture' is notoriously difficult to change, and 'institutionalisation' notoriously difficult to overcome. However, as Pellizzoni (2001:59) observes, 'seemingly intractable controversies may often be faced at the level of [discourse and] practices'. Perhaps the answer therefore lies in CT's core reciprocal interrelations between cultural bias, patterns of social relations and 'operational practices' (Figure 1; cf.6, 2011; 2015; 2016). In this way, 'learning-by-thinking' strategies (i.e. reflection) may be supplemented or even usurped in the process of adaptation by practical 'learning-by-doing' strategies.

This links notions of 'the institutional' to those of 'the practical' in institutional work. Importantly, Lawrence \& Suddaby (2006:219) recognise institutional work as 'intelligent, situated institutional action'. In recognition of this, for example, Simmons (2016) was able to use the above findings from his research to sit with public service managers, staff and user representatives, and discuss significant differences on the 'map' and how they might be reduced. This involved 'such purposive actions as the redrafting of standard operating procedures, establishment of new mechanisms for stakeholder 'voice', provision of new staff training opportunities, and new, 'nudge'-type activities in the phrasing and presentation of communications' (Simmons, 2016:949). Specific practical remedies that are applied in different policy contexts need to be bespoke to the policy issues they face. However, the tools of CT analysis can provide a guide for the deeply practical, situated 'institutional work' from which they might emerge. Effective navigation, particularly in an environment of complexity and ambiguity, therefore might be said to depend on greater reflection and the acquisition of such 'practical wisdom' through 'practical learning' (Rhodes, 2015).

\section{Conclusions}

Linking operational practices and systems back to institutionalised cultural biases and patterns of social relations, CT allows researchers to shine a light on new possibilities for addressing policy problems. Key reference points range from the relatively fast (e.g. following the direction given by our 'internal compass'), to the relatively slow (e.g. deeper 'reflection on values and norms and, by implication, the social structures which were instrumental in their development': Greenwood, 1998:1049). In short, it is argued here that dangers lie in wait if policy actors lean too heavily and uncritically on their 'internal compass' when navigating policy problems, and that deeper reflection is important for developing greater capacities for questioning (Turnbull, 2013), learning (Argyris, 1976) and adaptation (Lawrence \& Suddaby, 2006).

CT provides a useful framework for structuring research inquiry that leads to better institutional questioning, learning and adaptation in different (and especially complex) policy contexts. Yet this article argues that insufficient thought is given to such institutional issues. In particular, the article has sought to examine some of the evidence of this theory's potential and explain why it remains 
controversial. This has involved an attempt to move beyond the banality of 'birdspotting'-type narratives in CT analysis, and to lay some of myths about CT's practical value. The article raises the particular importance of operationalising CT using 'map' and 'compass' measurements as a way to make sense of these contexts. Relations of relative (in)congruence are particularly worthy of policy attention, whether to generate a creative institutional dialogue or to help avoid counterproductive institutional conflicts. Yet patterns of (in)congruence are not always readily visible. Researchers can therefore play an important role in robustly mapping out this terrain and providing this map as 'valid information' for policy debate. Meanwhile measurements of the compass show how likely it is that policy actors will engage on this terrain.

This article makes three further assertions: (i) that current prescriptive approaches for policy analysis using CT, such as the notion of 'clumsy solutions', generally lack the precision of measurement, (ii) that in conjunction, the 'map' and 'compass' provide researchers with the tools to support more effective policy navigation, and (iii) that more detailed understandings of the dynamics governing particular movements on the map are needed to effect appropriate institutional adaptations and change. As noted above, given that policy actors rarely possess an infallible 'internal compass', a reliable 'map' provides an invaluable tool against which to check they are on track.

To conclude, then, this article suggests that in the face of considerable complexity and uncertainty, orientation and navigation are demanding and ongoing tasks. However, by adding a map to policymakers' internal compass, researchers can provide a sense of where they are going and direction about how to find their way. There remains a need to connect these things with a detailed engagement of the terrain in order to align this research with practical action and institutional 'work'. It is hoped that through the 'map' and 'compass' approach outlined in this article there is a potential basis for moving further forward, and more speedily, in this direction.

\section{References}

Argyris, C. (1976) 'Single-Loop and Double-Loop Models in Research on Decision-Making', Administrative Science Quarterly, 21:363-375

Argyris, C. \& Schön, D. (1974) Theory in Practice, San Francisco: Jossey-Bass

Bate, P. \& Robert, G. (2007) Bringing User Experience to Healthcare Improvement, Oxford: Radcliffe Boholm, A. (1996) 'A Critique of Cultural Theory', Ethos, 61:64-84

Brett, J. (2000) 'Culture and Negotiation', International Journal of Psychology, 35(2):97-104

Brown, S. (1993) 'A Primer on Q Methodology', Operant Subjectivity, 16:91-138

Buck, S. (1989) 'Cultural Theory and Management of Common Property Resources', Human Ecology 17(1):101-116

Dake, K. (1991) 'Orienting Dispositions in the Perception of Risk', Journal of Cross Cultural Psychology 22:61

Dake, K. (1992) 'Myths of Nature', Journal of Social Issues 48(4):21-37 
Davy, B. (2016) Land Policy, London: Routledge

Douglas, M. (1966) Purity and Danger, London: Routledge \& Kegan Paul

Douglas, M. (1970) Natural Symbols, London: Barrie and Rockliff

Douglas, M. (1982) In the Active Voice, London: Routledge

Douglas, M. (1987) How Institututions Think, London: Routledge \& Kegan Paul

Douglas, M. (1992) Risk and Blame, London: Routledge

Durning, D. (1999) 'The Transition from Traditional to Postpositivist Policy Analysis: A Role for Q-

Methodology', Journal of Policy Analysis and Management, 18(3):389-410

Geva-May, I. (2002). 'Cultural Theory: The Neglected Variable in the Craft of Policy Analysis', Journal of Comparative Policy Analysis: Research and Practice, 4(3): 243-65.

Geva-May, I. with Wildavksy, A. (1997) An Operational Approach to Policy Analysis, Boston: Kluwer Geyer, R. \& Cairney, P. (2015) Handbook on Complexity and Public Policy, Cheltenham: Edward Elgar Greenwood, J. (1998) 'The Role of Reflection in Single and Double Loop Learning', Journal of Advanced Nursing, 27:1048-1053

Grint, K. (2005), Problems, Problems, Problems: The Social Construction of 'Leadership', Human Relations, 58(11):1467-94

Hardin, G (1968) 'The Tragedy of the Commons', Science, 162(3859):1243-1248.

Hirschman, A. (1970) Exit, Voice, and Loyalty, Cambridge: Harvard University Press

Hood, C. (1998) The Art of the State, Oxford: Oxford University Press

Hoppe, R. (2011) The Governance of Problems, Bristol: Policy Press

Kahneman, D. (2011) Thinking, Fast and Slow, New York: Farrar, Strauss and Giroux

Killion, J. \& Todnem, G. (1991) 'A Process for Personal Theory Building', Educational Leadership, 48(6):14-16

Klitgaard, R. (1997) 'Applying Cultural Theories to Practical Problems', in R. Ellis and M. Thompson (eds) Culture Matters: Essays in Honour of Aaron Wildavsky, Boulder, CO: Westview Press

Knott, D., Muers,S. \& Aldridge, S. (2008) Achieving Culture Change, London: Cabinet Office Lasswell, H. (1951) 'The Policy Orientation', In Lerner, D. \& Lasswell, H. (eds) The Policy Sciences, Stanford: Stanford University Press

Lawrence, T. \& Suddaby, R. (2006) 'Institutions and Institutional Work', in S. Clegg et al (eds.) Handbook of Organizational Studies, London: Sage

Mamadouh, V. (1999) 'Grid-Group Cultural Theory', GeoJournal, 47:395-409

Oliver, C. (1992) 'The Antecedents of Deinstitutionalization', Organization Studies, 13:563-588

Ostrom, E. (1990) Governing the Commons, Cambridge: CUP

Pellizzoni, L. (2001) 'The Myth of the Best Argument', British Journal of Sociology, 52(1): 59-86 
Perlis, C. \& Shannon, N. (2012) 'Role of Professional Organizations in Setting and Enforcing Ethical Norms', Clinics in Dermatology, 30(2):156-9

Quinn, R. (1988), Beyond Rational Management, San Francisco, CA: Jossey-Bass.

Rayner, S. (1992) 'Cultural Theory and Risk Analysis', in Krimsky, S. \& Golding, D. (eds.), Social Theories of Risk, Westport: Praeger

Rhodes, R. (2015) 'Recovering the 'Craft' of Public Administration in Westminster Government', Paper to Political Studies Association Conference, Sheffield, March-April

Ripberger, J., Swedlow, B., Silva,C. \& Jenkins-Smith, H. (2015) 'Operationalizing Cultural Theory in Survey Research', Paper to ECPR Annual Meeting, Montreal, August

Rittel, H. and Webber, M. (1973) 'Dilemmas in a General Theory of Planning', Policy Sciences, 4:155169

Schön, D. (1983) The Reflective Practitioner, London: Temple Smith

Simmons, R. (2016) 'Improvement and Public Service Relationships: Cultural Theory and Institutional Work', Public Administration, 94:933-952

Simon, H. (1955) 'A Behavioral Model of Rational Choice", Quarterly Journal of Economics, 69(1):99118

6, P. (2003) 'Institutional Viability: a neo-Durkheimian Theory', Innovation, 16(4):395-415

6, P. (2011) Explaining Political Judgement, Cambridge: Cambridge University Press

6, P. (2015) 'Structure and Political Agency, Thought Style and Strategy Schedules in Government', Paper to Political Studies Association Conference, Sheffield, March-April

6, P. (2016) 'How 'Natives' Work', Public Administration, 94 (4):1005-1022.

6, P. \& Swedlow, B. (2016) 'An Institutional Theory of Cultural Biases, Public Administration and Public Policy, Public Administration, 94 (4):867-880

Smythe, E. and Norton, A. (2007) 'Thinking as Leadership/Leadership as Thinking', Leadership, 3(1):65-90

Stewart, J. (1996) 'Moving Partnerships Forward.' Paper to Policy and Performance Review Network Conference, Warwick

Swedlow, B. (2002) 'Toward Cultural Analysis in Policy Analysis', Journal of Comparative Policy Analysis, 4(3):267-85.

Swedlow, B. (2007) 'Using the Boundaries of Science to do Boundary-Work Among Scientists:

Pollution and Purity Claims', Science and Public Policy, 34(9):633-643

Swedlow, B. (2011) 'Cultural Theory's Contributions to Political Science', PS: Political Science \& Politics, 44(4):703-10.

Swedlow, B. (2014) 'Advancing Policy Theory with Cultural Theory, Policy Studies Journal, 42(4):465483

Swedlow, B. (2017) 'Three Cultural Boundaries of Science, Institutions, and Policy', Review of Policy Research, 34(6):827-853 
Tansey, J. \& O'Riordan, T. (1999) Cultural Theory and Risk', Health, Risk \& Society, 1(1):71-90

Thompson, M. (2003) 'Cultural Theory, Climate Change and Clumsiness', Economic and Political Weekly, 38(48):5107-5112

Thompson, M. (2008) Organising and Disorganising, Axminster: Triarchy Press

Thompson, M., Ellis, R. and Wildavsky, A. (1990) Cultural Theory, Boulder, CO: Westview Press.

Turnbull, N. (2008) 'Harold Lasswell's 'Problem Orientation' for the Policy Sciences', Critical Policy Studies, 2(1):72-91

Turnbull, N. (2013) 'The Questioning Theory of Policy Practice', Critical Policy Studies, 7(2):115-131

Verweij, M. \& Thompson, M. (2006) Clumsy Solutions for a Complex World, Basingstoke: Palgrave MacMillan

Verweij, M. (2011) Clumsy Solutions for a Wicked World, Basingstoke: Palgrave MacMillan

Vickers, G. (1965) The Art of Judgment, New York: Basic Books

Wildavsky, A. (1987) 'Choosing Preferences by Constructing Institutions', American Political Science Review, 81(1):3-21

Wildavsky, A. (2006) Cultural Analysis, New Brunswick: Transaction 


\section{Using Cultural Theory to Navigate the Policy Process}

\section{Figures}

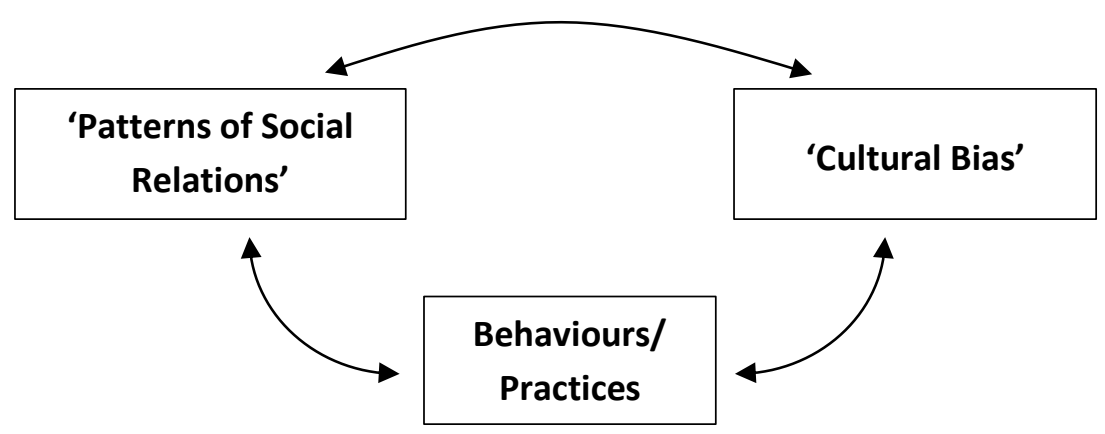

Figure 1: Constituting Institutions: Reciprocal Effects Between CT's Core Elements

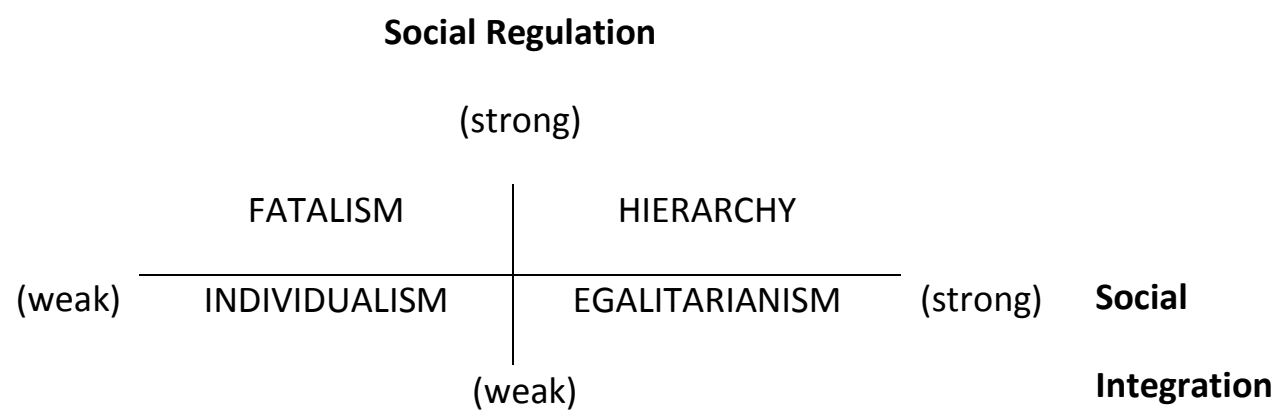

Figure 2: The Dimensions and Cultural Biases of CT 
Hood's Development of Cultural Theory for Public Management

\begin{tabular}{|c|c|c|c|}
\hline FATALIST & INDIVIDUALIST & HIERARCHIST & EGALITARIAN \\
\hline $\begin{array}{l}\text { Low co-operation } \\
\text { Rule-bound approach } \\
\text { to organisations }\end{array}$ & $\begin{array}{l}\text { Atomized approach } \\
\text { Stress on negotiation } \\
\text { and bargaining }\end{array}$ & $\begin{array}{l}\text { Socially cohesive } \\
\text { Rule bound approach } \\
\text { to organizations }\end{array}$ & $\begin{array}{l}\text { High-participation } \\
\text { structures } \\
\text { Every decision 'up for } \\
\text { grabs' }\end{array}$ \\
\hline $\begin{array}{l}\text { Ad hoc, minimalist } \\
\text { response to crises } \\
\text { Watchword: } \\
\text { resilience }\end{array}$ & $\begin{array}{l}\text { Responds to crisis } \\
\text { through resort to } \\
\text { competition and self- } \\
\text { interest } \\
\text { Watchword; } \\
\text { enlightened self- } \\
\text { interest }\end{array}$ & $\begin{array}{l}\text { Relies on expertise } \\
\text { and tighter procedures } \\
\text { in response to crises } \\
\text { Watchword: steering }\end{array}$ & $\begin{array}{l}\text { Based on participation } \\
\text { and whistle-blowing } \\
\text { Watchword: } \\
\text { community } \\
\text { participation }\end{array}$ \\
\hline $\begin{array}{l}\text { Weakness: Excessive } \\
\text { inertia or passivity }\end{array}$ & $\begin{array}{l}\text { Weakness: Individual } \\
\text { put before collective } \\
\text { benefit; lack of co- } \\
\text { operation and } \\
\text { comuption }\end{array}$ & $\begin{array}{l}\text { Weakness: Tendency } \\
\text { towards over- } \\
\text { ambitious projects; } \\
\text { misplaced trust in } \\
\text { expertise }\end{array}$ & $\begin{array}{l}\text { Weakness: Unwilling } \\
\text { to accept higher } \\
\text { authority, can lead to } \\
\text { unresolved feuds, } \\
\text { degenerating into co- } \\
\text { existence }\end{array}$ \\
\hline Control Approach & Control Approach & Control Approach & Control Approach \\
\hline $\begin{array}{l}\text { 'Chancism' } \\
\text { Organisation as } \\
\text { gaming machine }\end{array}$ & $\begin{array}{l}\text { 'Choicism' } \\
\text { Organisation as arena }\end{array}$ & $\begin{array}{l}\text { 'Bossism' } \\
\text { Organisation as a } \\
\text { ladder of authority }\end{array}$ & $\begin{array}{l}\text { 'Groupism' } \\
\text { Organisation as } \\
\text { collegial }\end{array}$ \\
\hline $\begin{array}{l}\text { Prone to a vicious } \\
\text { cycle whereby public } \\
\text { cynicism, rejection of } \\
\text { public participation, } \\
\text { lack of checks on } \\
\text { office holders and } \\
\text { inefficiency// } \\
\text { comuption of office } \\
\text { holders reinforce each } \\
\text { other }\end{array}$ & $\begin{array}{l}\text { Prone to rivaliry and } \\
\text { competition, plus the } \\
\text { problems of relying } \\
\text { on market- } \\
\text { mechanisms for policy } \\
\text { delivery }\end{array}$ & $\begin{array}{l}\text { Prone to prioritising } \\
\text { the interests of the } \\
\text { organisation above all; } \\
\text { needs well-understood } \\
\text { rules; and tends to } \\
\text { blame deviants in case } \\
\text { of problems, not the } \\
\text { organisation }\end{array}$ & $\begin{array}{l}\text { Four alternative } \\
\text { modes: } \\
\text { - traditional collegia } \\
\text { - transformational } \\
\text { - radical alternative } \\
\text { - elite democratic } \\
\text { community }\end{array}$ \\
\hline
\end{tabular}

Figure 3: An Example of Static CT Analysis for Conceptual Sensitisation (source: Hood, 1998) 


\begin{tabular}{|c|c|c|}
\hline Themes and Cultural Biases & How the service 'actually is' & How the service 'should be' \\
\hline \multicolumn{3}{|c|}{ 1: How fairness and equity issues are resolved } \\
\hline Cultural bias: Hierarchy & $\begin{array}{l}\text { 'Day care/Leisure/Housing services } \\
\text { are only be provided for those who } \\
\text { need them most' }\end{array}$ & $\begin{array}{l}\text { 'Day care/Leisure/Housing services } \\
\text { should only be provided for those } \\
\text { who need them most' }\end{array}$ \\
\hline Cultural bias: Individualism & $\begin{array}{l}\text { 'Individuals are given too little choice } \\
\text { about the kind of service they get' }\end{array}$ & $\begin{array}{l}\text { 'Individuals should be given more } \\
\text { choice about the kind of service they } \\
\text { get' }\end{array}$ \\
\hline Cultural bias: Egalitarianism & $\begin{array}{l}\text { 'Everybody in my community has the } \\
\text { same chance of getting the service' }\end{array}$ & $\begin{array}{l}\text { 'Everybody in my community should } \\
\text { have the same chance of getting the } \\
\text { service' }\end{array}$ \\
\hline Cultural bias: Fatalism & $\begin{array}{l}\text { 'It is a matter of chance or luck that } \\
\text { people get day care/leisure/housing } \\
\text { services' }\end{array}$ & $\begin{array}{l}\text { 'People should not expect to get day } \\
\text { care/leisure/housing services unless } \\
\text { they are lucky' }\end{array}$ \\
\hline \multicolumn{3}{|l|}{ 2: How knowledge is valued } \\
\hline Cultural bias: Hierarchy & $\begin{array}{l}\text { 'Users trust the experts to organise } \\
\text { the service' }\end{array}$ & $\begin{array}{l}\text { 'Users should trust the experts to } \\
\text { organise the service' }\end{array}$ \\
\hline Cultural bias: Individualism & $\begin{array}{l}\text { 'The service gives priority to what } \\
\text { individuals say they want' }\end{array}$ & $\begin{array}{l}\text { 'The service should give priority to } \\
\text { what individuals say they want' }\end{array}$ \\
\hline Cultural bias: Egalitarianism & $\begin{array}{l}\text { 'The service is run in line with the } \\
\text { views of users as a whole' }\end{array}$ & $\begin{array}{l}\text { 'The service should be run in line } \\
\text { with the views of users as a whole' }\end{array}$ \\
\hline Cultural bias: Fatalism & $\begin{array}{l}\text { 'I am wary of those who claim to } \\
\text { know what is best for the service' }\end{array}$ & $\begin{array}{l}\text { 'Users should be wary of anyone } \\
\text { who claims to know what is best for } \\
\text { the service' }\end{array}$ \\
\hline \multicolumn{3}{|c|}{ 3: How rules are set and policed } \\
\hline Cultural bias: Hierarchy & $\begin{array}{l}\text { 'The Council imposes strict rules to } \\
\text { tell users how to behave' }\end{array}$ & $\begin{array}{l}\text { 'The Council should impose strict } \\
\text { rules to tell users how to behave' }\end{array}$ \\
\hline Cultural bias: Individualism & $\begin{array}{l}\text { 'Individuals are free to use the } \\
\text { service however they like' }\end{array}$ & $\begin{array}{l}\text { 'Individuals should be free to use the } \\
\text { service however they like' }\end{array}$ \\
\hline Cultural bias: Egalitarianism & $\begin{array}{l}\text { 'Users know how to behave without } \\
\text { a lot of rules and regulations' }\end{array}$ & $\begin{array}{l}\text { 'Users should know how to behave } \\
\text { without a lot of rules and } \\
\text { regulations' }\end{array}$ \\
\hline Cultural bias: Fatalism & $\begin{array}{l}\text { 'There is no point having lots of rules } \\
\text { because people don't obey them' }\end{array}$ & $\begin{array}{l}\text { 'There is no point having lots of rules } \\
\text { because people won't obey them' }\end{array}$ \\
\hline \multicolumn{3}{|l|}{ 4: Courtesy and respect } \\
\hline Cultural bias: Hierarchy & $\begin{array}{l}\text { 'Users respect the experts' decisions } \\
\text { about the service' }\end{array}$ & $\begin{array}{l}\text { 'Users should respect the experts' } \\
\text { decisions about the service' }\end{array}$ \\
\hline Cultural bias: Individualism & $\begin{array}{l}\text { 'The staff accept that individuals } \\
\text { know best what they need' }\end{array}$ & $\begin{array}{l}\text { 'The staff should accept that } \\
\text { individuals know best what they } \\
\text { need' }\end{array}$ \\
\hline Cultural bias: Egalitarianism & $\begin{array}{l}\text { 'The service takes heed of what the } \\
\text { user community has to say' }\end{array}$ & $\begin{array}{l}\text { 'The service should take heed of } \\
\text { what the user community has to say' }\end{array}$ \\
\hline Cultural bias: Fatalism & $\begin{array}{l}\text { 'In my experience, users do not have } \\
\text { any power' }\end{array}$ & $\begin{array}{l}\text { 'Service users should not expect to } \\
\text { have any power' }\end{array}$ \\
\hline
\end{tabular}

Figure 4: Grouped Statements Measuring Cultural Congruence in Public Service Organizations (source: Simmons, 2016) 


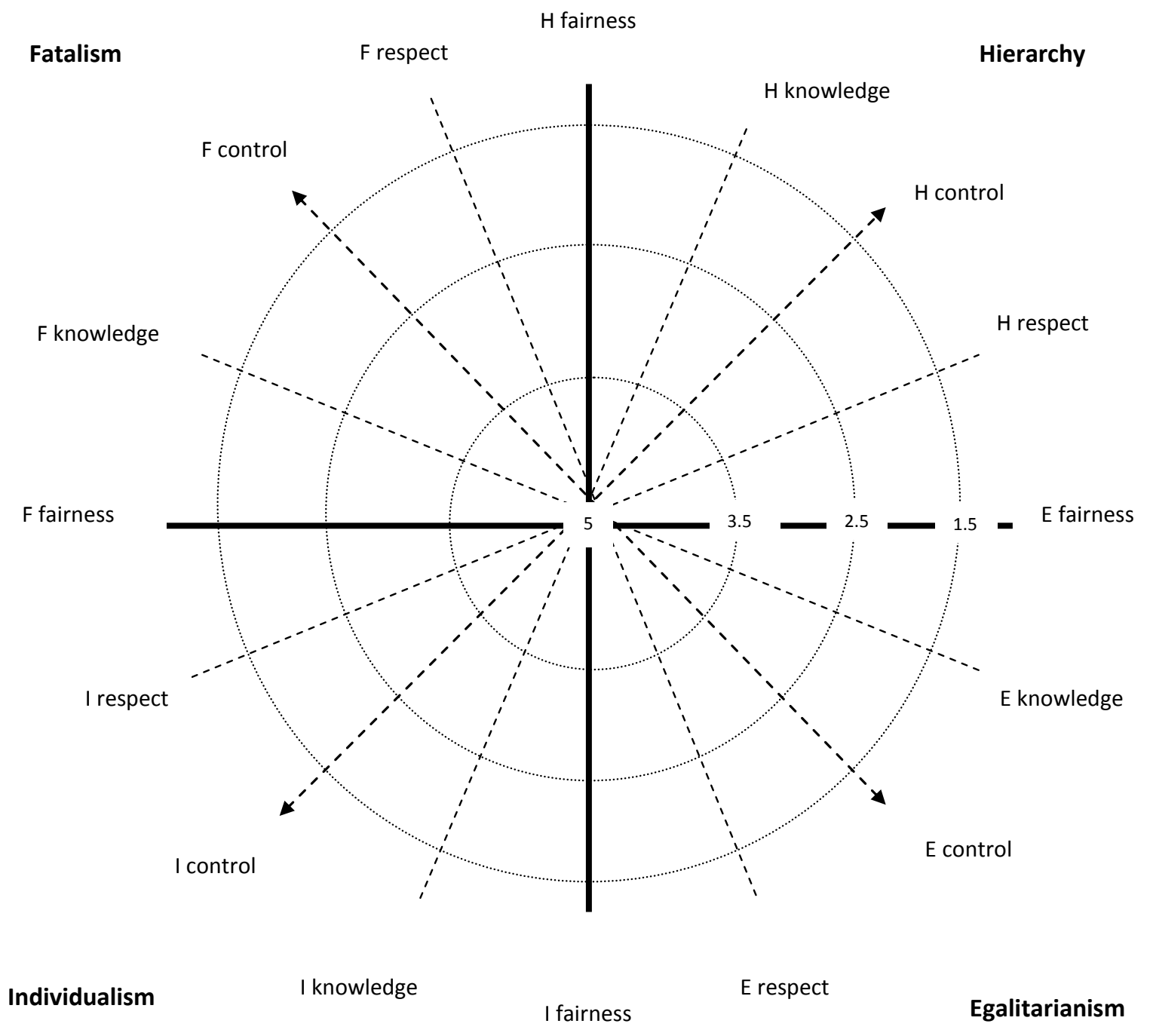

Figure 5: Key for Radial Plots in Figure 6 


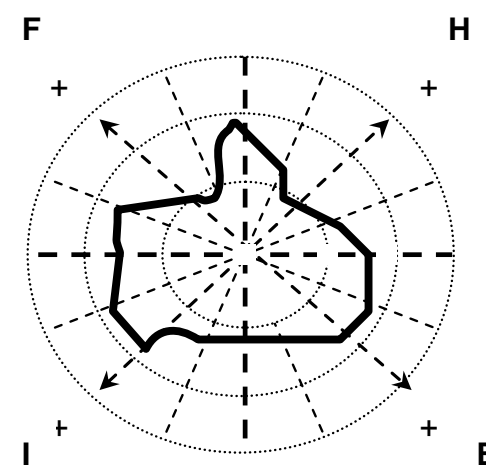

H $\quad \mathbf{F}$
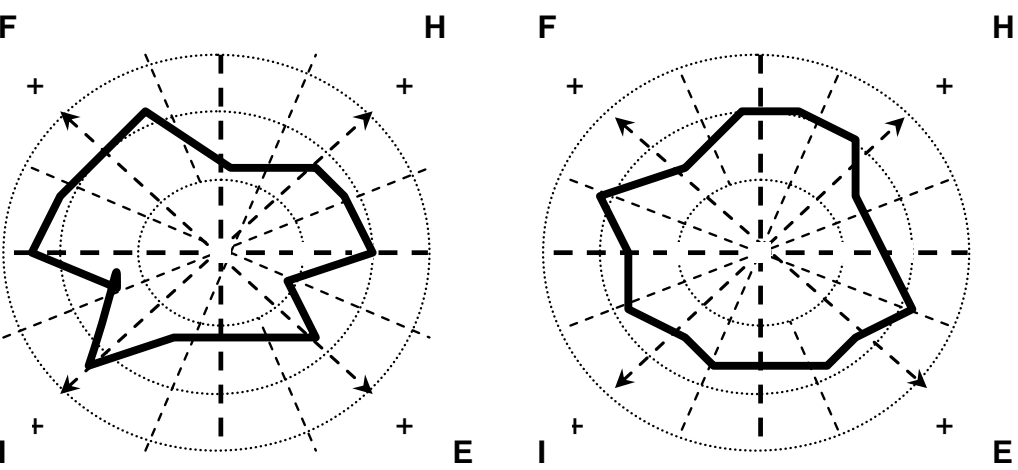

Leisure Services

Housing

Day Care

Figure 6a: "User Perceptions of How the Service "Is" (source: Simmons, 2016) $\mathbf{F}$ H $\quad F$
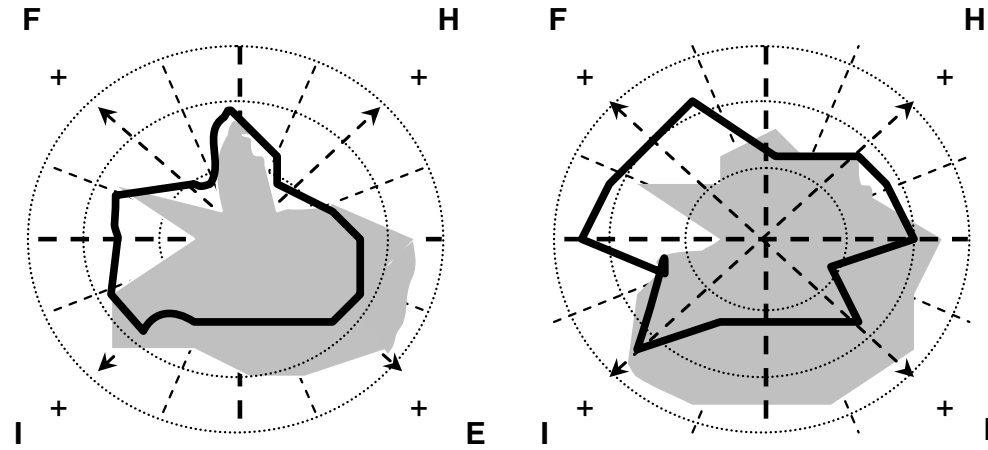

H $\quad F$

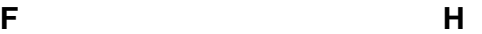

Leisure Services

Housing

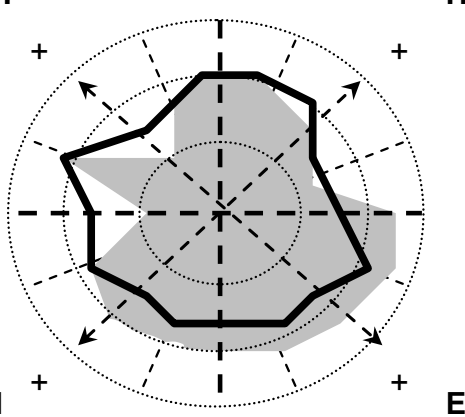

Day Care

Figure 6b: 'User Perceptions of How the Service 'Is' vs. How It 'Should Be"' (source: Simmons, 2016) 